\title{
Who Needs the Undercommons? Refuge and Resistance in Public High Schools
}

\author{
G. H. Greer \\ Concordia University
}

\begin{abstract}
This paper is a theoretical discussion of The Undercommons: Fugitive Planning and Black Study (Harney \& Moten, 2013) as a contribution to critical education in public schools. The undercommons serves here as an epistemic device, or a way of seeing and knowing, in relation to public education. The function of this device is to establish an appreciative view of student survival and activist behaviours and to centre educational policy as a potential mechanism of student exclusion. I propose that the practice of inclusion in schools coexists with unacknowledged operations of exclusion. The undercommons is employed as a lens to make such mechanisms of disenfranchisement apparent. I advocate here for an extension of inclusive education which, in addition to targeted supports for particular demographic groups, must concern itself with more general practices of disenfranchisement.
\end{abstract}

Keywords: social justice; inclusion; undercommons; disenfranchised students; public schools

G.H. Greer is a $\mathrm{PhD}$ candidate in Art Education at Concordia University. Informed by public school teaching and community youth work experiences, G.H.'s research focus is on inclusivity as a transformational force in educational, arts, and community settings.

Email: gia.greer@concordia.ca 
The commons as a place of communal investment and benefit is a concept that has come in and out of popular imagination since the time of Aristotle and before. Ecologist and philosopher Garrett Hardin (2009) has expressed concern with the individual interests of people who share in the common good, while philosopher and sociologist Henri LeFebvre (1992) discusses common space as produced by the way people share resources. Uniquely, The Undercommons: Fugitive Planning and Black Study (Harney \& Moten, 2013) describes a space found in the relationship between people who have been denied resources, and who are joined not by the common use or ownership of space, but by belonging within the community of those who have been excluded.

This paper is a theoretical discussion of The Undercommons as a contribution to critical education in public schools. The undercommons serves here as an epistemic device, or a way of seeing and knowing, in relation to public education. The function of this device is to establish an appreciative view of student survival and activist behaviours and to centre educational policy as a potential mechanism of student exclusion. I propose that the practice of inclusion in schools coexists with unacknowledged operations of exclusion. The undercommons is employed below as a lens to make such mechanisms of disenfranchisement apparent. I advocate here for an extension of inclusive education which, in addition to targeted supports for particular demographic groups, must concern itself with more general practices of disenfranchisement, which are described below.

For me, The Undercommons formed a link between personal experience as an outsider and educational policies, in which I am complicit, that create outsiders of students. In the following analyses, I attempt to transpose several key ideas from The Undercommons to a public school context in hopes of provoking a similar connection between readers and their students.

First, this writing progresses through a definition of terms, then to an outline of pertinent concepts from The Undercommons, and third, to a number of critical considerations related to inclusive education. In this third section, I pose questions intended to support dialogue in the local context of readers, not to provide data or teaching strategies. Readers in search of such resources will find some references to inclusive pedagogies in the second section under the headings Study and Planning. I conclude with a call to practice inclusion that not only supports disenfranchised individuals but also targets mechanisms of disenfranchisement in schools.

\section{Defining Inclusive Education (and its Exclusions)}

Inclusion, in Canada, began as a movement advocating for the full or partial integration of students with disabilities into mainstream classes (Carr, 2016), however it has recently been extended to refer to supports for diverse student and staff demographics in terms of racialization, and lesbian, gay, bisexual, transgender, and queer (LGBTQ) status (Ontario Ministry of Education, 2009).

The concept of inclusion has been criticized as inadequate to social justice concerns (de Oliveira Andreotti, Stein, Ahenakew, \& Hunt, 2015). Activist and legal scholar Dean Spade (2015), for example, calls for "more than legal recognition and inclusion, seeking instead to transform current logics of state, civil society security, and social equality" (p. 1). I argue that for inclusion to be relevant as a social justice movement it must be part of a transformative process. Inclusion must be accompanied by the recognition of existing inequity and rectifying action.

Broadly, the phrase social justice in this writing refers to advocacy for the equitable distribution of what Spade (2015) refers to as life chances. Life chances are factors which affect longevity: "housing, education, health care, identity documentation and records, employment, and public facilities, to name but a few" (Spade, 2015, p. xii). 
Specifically, I employ the concept of social justice here to interrogate the complicity of public schools in the inequitable distribution of life chances. Systems of education are implicated, for example, in the predictive relationship between disciplinary expulsion from public schools and the later incarceration of students subjected to expulsion (Skiba, Arredondo, \& Williams, 2014). Further inculpation occurs in the more frequent application of expulsion to black students when compared to non-black students who have committed similar offences (Edwards, 2016; Woodbury, 2016). This writing is concerned with the decisions that compose such patterns of injustice, and how it is possible that educators make quantitatively unjust decisions in the name of "fair school rules." To this end, I engage with ideas from The Undercommons.

The undercommons is a conceptual space composed of people who have been excluded from the commons, as explained above, and its entailed rights and privileges. I use the word "disenfranchised" throughout this paper to refer to both the inhabitants of the undercommons and analogous groups of students. Halberstam (2013) details the membership of the undercommons as "black people, indigenous peoples, queers and poor people" (p. 6).

It is important to acknowledge the experiences of particular demographics; however, it is crucial not to limit consideration of students here. As noted by Crenshaw (1991, 2012), the reality of intersecting identities is not reducible. Additionally, heterogeneous public school contexts may support or target any of a variety of vulnerable populations. Therefore, disenfranchisement in this writing refers primarily to the characteristic of being excluded from the common good; demographic attributions used to explain such exclusions are secondary.

Rather than focusing on and defining populations of concern, this writing attempts to focus on mechanisms of definition. That is to say that more can be learned about the mechanics of injustice from investigations of administrative systems than from examinations of vulnerable populations. Excessive disciplinary expulsion applied inequitably to black students, discussed above, is one example of unjust definition and exclusion. The Undercommons suggests that this problem originates in administrative action, not in black children. As such, attempts to "fix" the behaviour of students does nothing to address the issue, and in fact exacerbates the effects of prejudice.

Several concepts from The Undercommons are detailed below. I do not suggest that educators attempt to re-create the undercommons in schools. Rather this writing encourages an appreciative view of the undercommons with the dual goals of: recognizing intelligences of survival and activism among students; and targeting administrative mechanisms of exclusion.

\section{Undercommons: A Way in and What can be Found There}

The ideas in this section have made my teaching practice more responsive to the needs of students by drawing attention to the logics of student behaviour and making explicit the construction of fugitivity by administrative policy.

\section{Enter the Undercommons}

What is this conceptual space? And how does one enter it? I explicate a passage from The Undercommons here with the goal of clarifying these logistic concerns. Harney and Moten (2013) describe the Black Panther Party for Self Defense that organized neighbourhood patrols during the 1960s to protect community members from police brutality: "Against the law because they were generating law, they practiced an ongoing planning to be possessed, hopelessly and optimistically and incessantly indebted, given to unfinished, contrapuntal study of, and in, the common wealth" 
(p. 18) This quotation is exceptional because it simultaneously conveys seemingly contradictory meanings.

The phrase "against the law because they are generating law" begins the double narrative by describing the Panthers as both illegal and as lawmakers, because policy was enacted to suppress their activities. The varied definitions of three words in the rest of this quotation articulate at least two distinct meanings: "possessed" may mean "something owned, occupied, or controlled" (Possession [Def. 2], 2018) like a slave, or "domination by something (such as an evil spirit, a passion, or an idea)" (Possession [Def. 3], 2018); "indebted" may mean "owing money" (Indebted [Def. 2], 2018), or "owing gratitude or recognition" (Indebted [Def. 1], 2018); and "common wealth" sounds like one word meaning "nation" (Commonwealth [Def. 2], 2018) particularly colonial states which traded in slaves, but is written as two words meaning wealth held in common. Using the first set of definitions, the quote can be paraphrased roughly as: the Black Panthers were illegal and they planned to be slaves who owe money because of studying in formerly slaveowning states. Using the second set of definitions: the Panthers make their own laws and plan as though they are dominated by the passion of owing gratitude and recognition caused by the study of shared wealth. The first of these meanings is acceptable to forces of oppression. The second is a call to liberation. These possible meanings are made visible by the adjectives: "hopelessly" for the first interpretation, and "optimistically" for the second. Further, the word "contrapuntal" describes a song with two or more melodies, like this double narrative.

The two pertinent qualities of this quotation are: first, it may enable or disable multiple messages; and second, the content of these messages is directly related to the lived experience of the reader. Word play is used like the map hidden in a freedom song. You have to know where it is going in order to read how to get there, and the readers' relationship to emancipation determines the interpretation. Clarification is unnecessary and in fact undesirable. To use plain language would be to invite guards to a jailbreak. Giroux (1992) explores a similar line of thinking in relation to languages of academic complexity by stating "that the call for clarity suppresses difference and multiplicity" (p. 220).

In an education context, similarly, polyvocal communication occurs among students in the form of slang language, styles of dress, locations of congregation, and body language. Such signs are only partially visible, if at all, to teachers. A cryptic phrase between students may affirm friendship as an inside joke or be part of a campaign of harassment. The effects of these communications may be apparent to educators while precise meanings remain mysterious. Entrances to the undercommons are enabled by this kind of intertextuality, distinguishing the in-group from outsiders on the basis of reference comprehension.

In terms of the lived experiences of those who compose the undercommons, both in and outside of educational contexts, they are outsiders. Art education scholar David Pariser (2009) refers to "a device for distinguishing one in-group member from another" (p. 4) as a shibboleth, a term with biblical origins. A shibboleth marks individuals included in a group, while the undercommons is a kind of anti-shibboleth: distinguishing those who have been excluded. The undercommons is formed when these excluded individuals engage each other in the social activity that Harney and Moten (2013) describe as study.

\section{Study}

Study according to The Undercommons is the spontaneous sociality of lived experience: "study is already going on, including when you walk into a classroom and before you think you start a 
class, by the way" (Harney \& Moten, 2013, p. 112). Reserves of compassion, willingness to risk, capacity for expression, engagement with culture, and accented voices, all emerge from this kind of study.

I have yet to encounter a completely analogous concept in the field of education, however some similarity to study in the undercommons may be found in non-hierarchical modes of learning such as informal learning defined by Livingstone (2006); the pedagogy of Rancière's Ignorant Schoolmaster (1991); and Freire's (2005) Pedagogy of the Oppressed. Like informal learning study may include: "any activity involving the pursuit of understanding, knowledge, or skill that occurs without the presence of externally imposed curricular criteria" (Livingstone, 2006, p. 206). Harney and Moten might also agree with Rancière's (1991) statement that frames explanation as a way of subjugating learners: "the child who is explained to will devote his intelligence to the work of grieving: to understanding, that is to say, to understanding that he doesn't understand unless he is explained to" (p. 8). Unlike these approaches, however, study in the undercommons is not necessarily intentional and is always social.

Freire's pedagogy of the oppressed is most similar to study in the undercommons because of its social nature and standpoint outside of power. However, there is a nuanced distinction: Freire's pedagogy is intentional and emancipatory, while study in the undercommons is commonplace and unpredictable. Freire's approach may be categorized more appropriately as a component of planning, which is discussed below.

Social justice educators familiar with the concept of prior learning or knowledge may see similarities between acknowledging study in the undercommons and considering learners' "multiple social identities, interests, expectations, needs, prior experiences, lived realities, and learning preferences" (Adams, Bell, Goodman, \& Joshi, 2016, p. 57). The important difference between prior learning and study is that the former works in service of present classroom instruction, while study is its own outcome.

In the undercommons, Harney and Moten (2013) state that:

... [S]tudy is what you do with other people. It's talking and walking around with other people, working, dancing, suffering, some irreducible convergence of all three, held under the name of speculative practice... The point of calling it 'study' is to mark that the incessant and irreversible intellectuality of these activities is already present. (p. 110)

The use of the word study radically democratizes the idea of learning; it is a challenge to perceptions of curricular education as a monopoly of knowing.

Over, beyond, and around curricular learning, study from the undercommons takes note of social dynamics. Survival in the broadest sense of the term motivates study. In a less hostile environment survival can be joyful: the "notion of a rehearsal - being in a kind of workshop, playing in a band, in a jam session, or old men sitting on a porch, or people working together in a factory" (Harney \& Moten, 2013, p. 110). However, students in the undercommons experience the hostility of being "different" in a public school context. They know when visibility is against their best interests. Gifted students may pretend not to know answers while illiteracy is deftly covered with bathroom breaks. These are also expressions of study. Study is a relentless experimentation, incessantly discovering accomplices and employing protective daydreams.

I do not advocate here for public school pedagogy in the style of the undercommons; rather I propose an appreciative view of study as a form of refuge. Seeing and knowing through the undercommons may allow teachers to recognize intelligence in forms of study that act in service of joy and resilience. Methods such as critical culture sustaining pedagogy (Paris \& Alim, 2014), strengths-based pedagogy (Galloway, Reynolds, \& Williamson, 2016), and culturally responsive 
teaching (Gay, 2013) may help educators recognize and support study among our students, lest survival skills be mistaken for misbehaviour.

\section{Planning}

While study in the undercommons is a sociality that provides refuge, joy, and resilience, planning is the ongoing process of resistance which protects study. In the terms of complexity theory, planning creates the conditions for study to emerge. Planning defends study, for example, by attending to methods, when economic forces are oriented toward outcomes. In such a case, study thrives in the fascination required to build a car from scratch but is extinguished by a production line. Planning may then take the form of activism against the process of de-skilling workers. Generally, study is in trouble where labour is detached from purpose, discovery, and agency; and planning poses resistance to such divisions. Resistance may take a passive form like absenteeism or an active form like student strikes; it is an ongoing social experiment.

The subjects of difference who inhabit the undercommons initiate planning in support of further difference: "planning in the undercommons is not an activity, not fishing or dancing or teaching or loving, but the ceaseless experiment with the future presence of the forms of life that make such activities possible" (Harney \& Moten, 2013, p. 74). Importantly, "[p]lanning is self-sufficiency at the social level, and it reproduces in its experiment not just what it needs, life, but what it wants, life in difference..." (p. 76). Planning resists the austerity of conformity.

Difference may bring the concept of diversity to mind for social justice educators. There are a number of distinctions between the difference that propels planning in the undercommons and diversity as it is understood in the field of education. Social justice education organized around diversity involves "eliminating the injustice created when differences are sorted and ranked in a hierarchy that unequally confers power..." (Adams, Bell, Goodman, \& Joshi, 2016, p. 3, emphasis in original). In this sense, equitable diversity is an end goal that is, significantly, often supported by the implementation of policy. Planning, on the other hand, is a process, rather than an outcome, that resists policy, as explained below.

Planning appears distorted, if at all, from the commons where the rules are made: "Because from the perspective of policy it is too dark in there, in the black heart of the undercommons, to see" (Harney \& Moten, 2013, p. 79). Planning may become invisible or appear criminal in the light. Historical examples of such distortions are plentiful. The Freedom Riders were planning in 1961, boarding buses into their own brutalization to desegregate the southern United States; in the light of curricular history, Freedom Riders disappear and are replaced by parliamentary motions. There was planning at the Stonewall Riots in June of 1969 when homeless queer kids led by trans women of colour revolted against police brutality; the political necessity of Stonewall disappears in the parade lights of Pride every year on its own anniversary. Planning made visible but distorted is apparent in current events in the criminalization of self-preservation: from immigration (Ackerman \& Furman, 2013), to activism (Matthews \& Cyril, 2017; Alonso, Barcena, \& Gorostidi, 2013), to panhandling (Chesnay, 2013).

Educators who wish to see the planning of the undercommons, or to make it visible to students, must research to discover the exclusions of curriculum. When we include stories like the Stonewall Riots or the Freedom Riders in our teaching, we offer a connection to students who see their lives reflected therein. Stories of resistance to injustice, particular to local contexts, are important educational resources. In addition to these, pedagogical models which support the development and scholastic direction, of planning skills among students include: problem-based learning 
(Walker, Leary, Hmelo-Silver, \& Ertmer, 2015), choice-based art education (Douglas, \& Jaquith, 2009), critical media literacy (Funk, Kellner, \& Share, 2016), and anti-oppressive education (Kumashiro, 2000).

\section{Policy}

From the perspective of the undercommons, policy inevitably conflicts with the forms of study and planning described above. Policy is the instrument of efficiency; it seeks measurable, predictable outcomes. The immeasurable social experiments and emerging differences of planning and study cannot be reconciled with administrative control as exercised through policy.

Policy from the perspective of the undercommons operates under three rules. First, it diagnoses planners as problematic and prescribes itself as the solution; "This is the first rule of policy. It fixes others" (Harney \& Moten, 2013, p. 78). Second, policy requires the participation of planners in the fixing of themselves; "Participating in change is the second rule of policy." (Harney \& Moten, 2013 , p. 80). In this way, participants implicate themselves in order to fulfill the third rule of policy: that "wrong participation" (Harney \& Moten, 2013, p. 81) provokes all manner of crises. If there is no crisis then the participant is fixed and may be deputised in order to fix others. More commonly, any crisis at all proves that policy was right about the planners all along; and of course, they were bound to fail. The circular logic of policy as viewed from the undercommons reflects what Spade (2015) calls administrative violence.

Spade (2015) details a story which I relate here to clarify the operations of policy. Bianca, a trans girl, was sent home from her high school in 1999 for wearing clothing that affirmed her gender. She was not allowed to return to her classes. Bianca's parents called the school and received no response. Spade met Bianca in 2002 when she was homeless, unemployed, and attempting to leave an abusive relationship. Bianca had enrolled in a welfare work program but was outed as a trans woman by her male identification (ID). She was subsequently harassed and forced to quit, losing her income and making her ineligible for Medicaid. She became homeless, and because of her male ID she was barred from women's shelters and fearful of further abuse at shelters for men. Without an address, medical benefits, or an income Bianca was unable to complete the process to correct her ID and could not afford the hormone treatments that allowed her to maintain a feminine appearance. Bianca's ability to pass as a cisgender woman protected her on the street from further harassment by both the public and the police. In order to afford hormone injections, Bianca engaged in sex work. The injections were not regulated because they had to be obtained illegally which placed Bianca at increased risk of infection by HIV, hepatitis, and other diseases.

Although Bianca's story is not recent, the factors that contributed to her difficulties are relevant: transgender youth are still significantly over-represented in groups of early school leavers, homeless youth, and survivors of violence (Morton et al., 2018; Keuroghlian, Shtasel, \& Bassuk, 2014).

In the language of the undercommons Bianca planned to survive by expressing her gender, but this plan was subverted by school policy, causing her not to graduate and significantly reducing her prospects for employment. Following the first rule of policy according to the undercommons, Bianca's school would not accept her attendance until she fixed her gender. Bianca then followed the second rule of policy and made attempts to become a participant. She tried to stay at shelters and enrolled in a social welfare work program. In each of these cases, she experienced the crisis of harassment. Following the third rule of policy, these crises were framed as the result of Bianca's 
wrong participation: she did not have the right identification. For survival, Bianca must then become a fugitive by engaging in criminalized activity: sex work and the illegal procurement of hormones.

In an educational context, considering policy, according to The Undercommons, pushes educators to ask how the rules in our schools create, rather than respond to, fugitivity among students.

\section{Fugitivity}

Being a fugitive according to The Undercommons means being marked as an outsider. Fugitivity happens to people when: first they act, and second policy outlaws those actions. But fugitivity must also be embraced. Those who refuse the rules of policy, as outlined above, become fugitive. Fugitives will not be fixed, refuse to participate, and deny responsibility for the crises that befall them. Fugitivity recognises systemic racism, classism, ableism, and cis/heteronormativity in the disallowance of demographic-specific behaviour. It is fugitive sociality that composes the undercommons in order to provide refuge and resistance.

In high schools, the undercommons provides social refuge in the form of patient listening and covert smiles to: hat wearing, cell phone texting, hall running, affection displaying, fugitive students; and granola bar giving, grade fudging, student failing, smiling before Christmas, fugitive teachers. These now-fugitive activities are planning behaviours, they sustain study for those that commit them. These things have been happening since before policy determined that education is a predictable and measurable thing. Fugitive planners generate study with unforeseeable ends and immeasurable learning. Turning planners into fugitives has some effects: ease of administration and evaluation is one; the reinforcement of unjust hierarchies is another.

Working for the equitable distribution of life chances in schools means understanding that policy which bans particular kinds of head covers, sports jerseys, shoes, and other indicators of community membership, make fugitives of the students who wear them. To maintain equitable education - rather than hierarchies of ability, racialization, and income - it is vital that educators deeply question whether school rules disproportionately affect vulnerable people. People who predominantly do not experience prejudice and who wish to support those who do must listen for coded language like 'urban' to mean black, 'artistic' to mean gay, and the names of geographic locations which mean poor. To be for social justice requires resistance to unjust policy which creates fugitives, intentionally or not, of vulnerable school community members.

\section{Antagonism}

The Undercommons describes a sense of "general antagonism" which arises in resistance to unjust policy. General antagonism is a "sense of dispossession, and possession by the dispossessed" (Harney \& Moten, 2013, p. 109). This refers to the dispossession one experiences as an outsider to a dominant group and the subsequent experience of being possessed or claimed as a fellow outsider by those who are similarly dispossessed. The general antagonism occurs when disenfranchised people find each other and allow the differences between them to propel planning.

The general antagonism is a site of experimentation. As a queer person, I am often obliged to experiment with antagonism. My regular behaviour may be interpreted as an act of opposition depending on the context. Revealing the gender of a partner, expressing affection, or using a public restroom, all hold the potential of opposing cis/heteronormative values when such prejudice exists 
around me. I may experiment, for example, by discussing politics in the abstract before revealing life details to determine how much of myself is reasonable to express. According to The Undercommons, "whereever and whenever that experiment is going on within the general antagonism the undercommons is found" (p. 109).

To give an example of the general antagonism's dispossession and repossession I must speak from the perspective of a student. As a teacher, I have been the authority figure in my classrooms no matter how casually or democratically I exercised this power. Teachers in our own classrooms reside in the commons, not the undercommons, particularly in relation to students over whom we have power.

At the start of class one day, a professor of mine brought forward a news story about a notorious academic who refused to use gender-neutral pronouns. This story was intended as a prompt for a discussion of free speech. As the only queer-identified student in the room, and someone who uses non-binary pronouns, I felt removed from the rest of the group: my gender was now a topic of debate. Speaking from a place of exhaustion, I remember repeating: "this is not interesting; this is my everyday."

Kindly, a classmate interjected. She calmly explained to the professor that debating the existence of non-binary genders is analogous in some ways to debating the freedom of racist or anti-Semitic speech. If those issues were not appropriate to our discussion, as the professor agreed they were not, then we should not treat gender identity differently. My classmates expressed their assent, and I felt repossessed by a supportive cohort. The speaker may have had insight into dispossession by way of her own experiences. In any case, as a student, she was in a position of diminished authority when compared to the professor, and she experimented with her own safety in order to reclaim me as part of her group. That student exercised the general antagonism, and we became a tiny undercommons.

The practice of general antagonism is a social experiment which creates the undercommons, a virtual space that is cohabited rather than inhabited because it is formed between people and therefore has always more than one occupant. Dispossessed individuals who form refuge and resistance with and for each other produce the undercommons. In a high school context, the virtual space of the undercommons is created by affiliation among individuals passing out of belonging with the functions of administrative policy and into belonging with each other.

An awareness of the information gathering and community generating functions of the general antagonism in school contexts is an important consideration for educators tasked with disciplining antagonistic students. Further exploration of alternative interpretations of student antagonism is discussed below under Behaviour as Communication.

\section{What Good is the Undercommons?}

Extending inclusion as a support for disenfranchised students requires consideration and labour. The undercommons is founded in celebration of difference and originates at a vantage point that makes explicit the ways that particular students are excluded from common resources and life chances. As such, attempting to see and know through the undercommons has the potential to increase educators' capacity to recognize and rectify injustice in schools. In addition to the important demographic-specific work of inclusion, the undercommons as an epistemic device provides a starting point for deploying inclusion as resistance to mechanisms of disenfranchisement. 
I identify here three areas in particular where consideration of The Undercommons supports the inclusion of disenfranchised students. These are: first, any observable demographic patterns among students affected by school rules; second, alternative interpretations of student behaviours; and third, consideration of the need for social connections among students. I outline these below along with some of the thoughts and questions raised by a perspective informed by the undercommons.

The discussion in this section, along with relevant scholarship, and educators' knowledge of their own school community is intended as a starting point for readers to target locally relevant mechanisms of exclusion. Some resources are listed above under Study and Planning although individual school settings will require unique approaches. School community members are deeply informed about their own school culture, and that information must be accounted for before theoretical discussions like this one can be usefully applied.

\section{Patterns of Effect}

The first area of interest highlighted by this paper's interpretation of The Undercommons is the overall pattern of effects which stem from school rules. Such patterns may be explored by asking: first, whether intentionally or not, are there groups of students made fugitive by policy? And second, are there expressions of students' identities which are not acceptable at school? Affected students may include those: who commonly dress outside of school in a way that is not permitted in school; who are barred from accessing concentration supports such as physical movement, music, and quiet spaces; and who do not see people like themselves reflected in learning materials or the demographics of school staff.

Further questions include: Are there ways that policies can be shifted to make schools more welcoming of these students in particular? Where segregation exists, what mechanisms reward or enforce it? Do common extracurricular activities require inaccessible cultural knowledge? What does welcome look like within disenfranchised groups? Is it possible for the school to create such conditions? Is the food in the school affordable and appealing across cultures? How might administrators defend against cultures of overwork and burnout in order to afford teachers the time and energy to connect with resources and explore these questions? In your own school context, what are the patterns of inclusion and exclusion?

\section{Behaviour as Communication}

A second area that may be illuminated differently upon consideration of the undercommons is the alternate meanings of student behaviour, particularly behaviour that conflicts with school rules or appears antagonistic. Here I reflect on a common example of antagonism as an experiment and resistance: boundary testing on the part of students. Regardless of its particular expressions, what can be learned from this behaviour?

Primarily, boundary testing indicates that the student does not understand boundaries. A boundary can only be tested when it is unknown, otherwise it is being either affirmed or transgressed. The second thing student boundary testing signifies is that the student is concerned about the rules. Tests are performed by people who are looking for information, not by those who are indifferent. Thirdly, boundary testing reveals a breakdown of usual modes of communication. Perhaps the student has experiences, such as having been lied to, which make spoken words seem unreliable. I do not write in favour of acting out as a method of discerning boundaries in public 
schools. I do wish to highlight that antagonism is a basic and functional strategy for covertly gathering information; if it did not work, it would not be so common.

Reflecting on these nuances, why might a student, or any rational person, engage in antagonistic behaviour? What information does the student attain as a consequence of this behaviour? Is the information conveyed orally in school settings generally aligned with the student's experiences? How can teachers and administrators become credible sources of information?

As a child, I remember being warned by teachers that their trust would be earned and not given. Educators of disenfranchised students would do well to remember this adage and employ it in reverse. As adults, we have the opportunity to model a healthy capacity for trust while our students may not yet have developed this skill.

\section{Social Connections}

Our ability as adults to model healthy ways of relating connects to the final area of reflection: the need for social connections among disenfranchised students. Many punitive measures within schools hinge on the social isolation of students: suspension, detention, and sending students to the office, for example. Consider that what is perceived as misbehaviour may be the student's attempt, consciously or not, to gather information or even, ironically, to resist policies which threaten to categorize the student as a fugitive. Imagine the state of mind that leads to such behaviour: confusion about boundaries; apprehension about the credibility of school staff; and an expectation that normal behaviour, in the world of the student, will be found unacceptable by school authorities. If the student has experience of discovering school rules only after transgressing them, there may also be anxiety about which behaviours, in particular, will be problematic. Such a student will certainly seek social refuge. If the student is isolated from positive social ties, by expulsion or isolating forms of detention, it cannot be surprising when destructive socialities emerge. "Bad crowds" are more often created than fallen into, by young people seeking social connection.

Bearing these possibilities in mind, how can reasonable order be supported within schools without the isolation of vulnerable young people? Is it possible to create preventative, positive social engagement within school communities? Could restorative practices with a social component be instituted in place of suspension and detention?

Above are only three avenues of critical inquiry that arise from a reading of the undercommons. Readers may follow another line of thinking to investigate the nature of exclusion in their own schools. The purpose of such reflection is to isolate the factors which perpetuate the disenfranchisement of vulnerable students.

\section{Targeting Exclusion in Public Schools}

I have attempted to employ the undercommons in this writing as a way of seeing and knowing. The Undercommons is used here to detail the pathologizing encounters which occur between administrative structures and individuals who are found to be deficient or fugitive according to policy. I hope to have made two things explicit here: first, the value of study or learning as a social project unrelated to administrated education; and second, the methods by which fugitivity can be created by school systems rather than solely committed by students.

Conventionally, inclusion relies on the identification of individual students who need support. In addition to that important work, inclusion that targets disenfranchisement would rely on the 
identification and cessation of exclusionary school practices, such as the excessive use of disciplinary expulsion. I argue for inclusion that not only supports marginalized students, but that also exposes and disables the means through which school systems contribute to the creation of student marginalization.

The inclusion of disenfranchised students means bringing practices of exclusion to the centre of our teaching in order to expose and dismantle them. The identification of exclusionary practices is meant to be supported here by a three-way conversation between: the lived experiences of readers in their school communities; relevant scholarship such as the resources referenced under the headings Study and Planning; and critical questions like those raised under the heading What Good is the Undercommons. Targeting school operations which create student disenfranchisement will benefit not only students who have been identified as marginalized, but also those with stories that are unknown to schools, and those who struggle to support their peers in isolation.

Wherever systems mark the in and outside of functionality and normalcy, a need is created for refuge among the excluded, and the site is set for resistance. In such situations, the undercommons is the underside of administration. Teachers on the front line of educational inclusions and exclusions may become more deeply informed about the effects of school systems on disenfranchised students by employing the undercommons as an epistemic device. By seeing and knowing through the undercommons, we may recognize the strengths that learners employ in service of survival and activism, and invite these forms of study into conversations with curricula. When we alter our teaching practices according to such recognitions we affect the inclusivity of educational systems that are, after all, composed of teachers. 


\section{References}

Ackerman, A. \& Furman, R. (2013). The criminalization of immigration: Contexts and consequences. Durham, NC: Carolina Academic Press

Alonso, C., Barcena, I., \& Gorostidi, I. (17 December, 2013) Repression and criminalization of the ecologist movement in the Basque country: The case of the high speed train project. Oñati Socio-Legal Series, 4(1). Retrieved from https://papers.ssrn.com/sol3/papers.cfm?abstract_id=2368880

Adams, M., Bell, L. A., Goodman, D. J., \& Joshi, K Y. (Eds.). (2016). Teaching for diversity and social justice third edition. New York, NY: Routledge.

Carr, J. R. (2016) A conceptual and legal framework for inclusive education. Toronto, ON: ARCH - Disability Law Center.

Chesnay, C. T. (2013). Taming disorderly people one ticket at a time: The penalization of homelessness in Ontario and British Columbia. Canadian Journal of Criminology and Criminal Justice, 55(2), 161-185.

Crenshaw, K. (1991). Mapping the margins: Intersectionality, identity politics, and violence against women of color. Stanford Law Review, 43(6), 1241-1300.

Crenshaw, K. (2012). From private violence to mass incarceration: Thinking intersectionally about women, race, and social control. UCLA Law Review, 59(6), 1418-1472.

Commonwealth. (9 May 2018). In Merriam-Webster.com. Retrieved from https:/www.merriamwebster.com/dictionary/commonwealth

de Oliveira Andreotti, V., Stein, S., Ahenakew, C., \& Hunt, D. (2015). Mapping interpretations of decolonization in the context of higher education. Decolonization: Indigeneity, Education \& Society, 4(1), 21-40.

Douglas, K. M., \& Jaquith, D. B. (2009) Engaging learners through artmaking: Choice-based art education in the classroom. New York, NY: Teachers College Press.

Edwards, L. (2016). Homogeneity and inequality: School discipline inequality and the role of racial composition. Social Forces, 95(1), 55-75. doi:10.1093/sf/sow038

Freire, P. (2005). Pedagogy of the oppressed. New York, NY: Continuum

Funk, S., Kellner, D., \& Share, J. (2016). Critical media literacy as transformative pedagogy. In M. N. Yildiz,\& J. Keengwe (Eds.), Handbook of research on media literacy in the digital age (pp. 1-30). Hershey, CA: IGI Global

Galloway R., Reynolds B., \& Williamson J. (2016). Strengths-based teaching and learning approaches for children. In: S. Fan \& J. Fielding-Wells (Eds.), What is next in educational research?(pp. 213-222). Rotterdam: Sense Publishers.

Geneva, G. (2013). Teaching to and through cultural diversity. The Ontario Institute for Studies in Education of the University of Toronto Curriculum Inquiry, 43(1), 48-70.

Giroux, H. A. (1992). Language, difference, and curriculum theory: Beyond the politics of clarity. Theory into Practice, 31(3), 219-227. doi:10.1080/00405849209543546

Halberstam, J. (2013). The wild beyond: With and for the undercommons. In S. Harney \& F. Moten (Eds.), The undercommons: Fugitive planning \& black study, (pp. 2-13). New York, NY: Minor Compositions.

Hardin, G. (2009). The tragedy of the commons. Journal of Natural Resources Policy Research, 1(3), 243-253.

Harney, S., \& Moten, F. (2013). The undercommons: fugitive planning and black study. New York, NY: Minor Compositions. 
Indebted. (18 May 2018) In Merriam-Webster.com. Retrieved from https://www.merriamwebster.com/dictionary/indebted

Keuroghlian, A. S., Shtasel, D., \& Bassuk, E. L. (2014). Out on the street: A public health and policy agenda for lesbian, gay, bisexual, and transgender youth who are homeless. American Journal of Orthopsychiatry, 84(1), 66-72. doi:10.1037/h0098852

Kumashiro, K. K. (2000). Toward a theory of anti-oppressive education. Review of Educational Research, 70(1), 25-53.

Lefebvre, H. (1992). The production of space (D. Nicholson-Smith, Trans.). Oxford, UK: WileyBlackwell.

Livingstone, D. W. (2006). Informal learning: Conceptual distinctions and preliminary findings. In Z. Bekerman, N. C. Burbules, D. Silberman-Keller, Z. Bekerman, N. C. Burbules \& D. Silberman-Keller (Eds.), Learning in places: The informal education reader (pp. 203227). New York, NY,: Peter Lang Publishing.

Matthews, S. \& Cyril, M. (19 October 2017). We say black lives matter. The FBI says that makes us a security threat. The Washington Post. Retrieved from: https://www.washingtonpost.com/news/posteverything/wp/2017/10/19/we-say-blacklives-matter-the-fbi-says-that-makes-us-a-security-threat/?utm term=.5aaba2e49af5

Morton, M. H., Dworsky, A., Matjasko, J. L., Curry, S. R., Schlueter, D., Chávez, R., \& Farrell, A. F. (2018). Prevalence and correlates of youth homelessness in the United States. Journal of Adolescent Health, 62(1), 14-21.

Ontario Ministry of Education. (2009). Realizing the promise of diversity: Ontario's equity and inclusive education strategy. Toronto, ON: Ontario Ministry of Education.

Paris, D, \& Alim, H. (2014). What are we seeking to sustain through culturally sustaining pedagogy? A loving critique forward. Harvard Educational Review, 84(1), 85-100.

Pariser, D. (2009). Arts-Based research: Trojan horses and shibboleths: The liabilities of a hybrid research approach: What hath Eisner wrought?. Canadian Review of Art Education: Research \& Issues, 36(1), 1-18.

Possession. (14 May 2018). In Merriam-Webster.com. Retrieved from https://www.merriamwebster.com/dictionary/possession

Rancière, J. (1991). The ignorant schoolmaster: Five lessons in intellectual emancipation. Stanford, CA: Stanford University Press.

Skiba, R. J., Arredondo, M. I., \& Williams, N. T. (2014). More than a metaphor: The contribution of exclusionary discipline to a school-to-prison pipeline. Equity \& Excellence in Education, 47(4), 546-564. doi:10.1080/10665684.2014.958965

Spade, D. (2015). Normal life. Durham, UK: Duke University Press.

Walker, A. E., Leary, H., Hmelo-Silver, C. E., \& Ertmer P. A. (2015). Essential readings in problem-based learning. West Lafayette, IN: Purdue University Press.

Woodbury, R. (12 December 2016). African-Nova Scotian students being suspended at disproportionately higher rates. CBC News Nova Scotia. Retrieved from http://www.cbc.ca/news/canada/nova-scotia/african-nova-scotian-students-suspensionnumbers-1.3885721 